\title{
Impulsar la ciencia, tecnología e innovación para el desarrollo sostenible
}

Ghandi decía: «La India es demasiado pobre, como para darse el lujo de no hacer ciencia». Cito a este extraordinario líder para romper con el paradigma que señala que la ciencia es el privilegio de los países desarrollados. La investigación científica, el desarrollo de tecnología y la innovación productiva son las únicas herramientas que tenemos los países como el Perú para llegar a ser uno del primer mundo. Nuestros recursos naturales son

Por Rómulo Mucho solo eso: recursos naturales. $\mathrm{Su}$ sola tenencia no garantiza siquiera el inicio del desarrollo sostenible. Una muestra de ello son, sin lugar a dudas, los ciclos en los que los precios internacionales de los minerales bajan. Inmediatamente, se ve afectado nuestro $\mathrm{PBI}$, nuestro volumen de exportaciones, la captación por parte del Estado del impuesto a la renta y la consecuente menor distribución del canon minero hacia las regiones. 


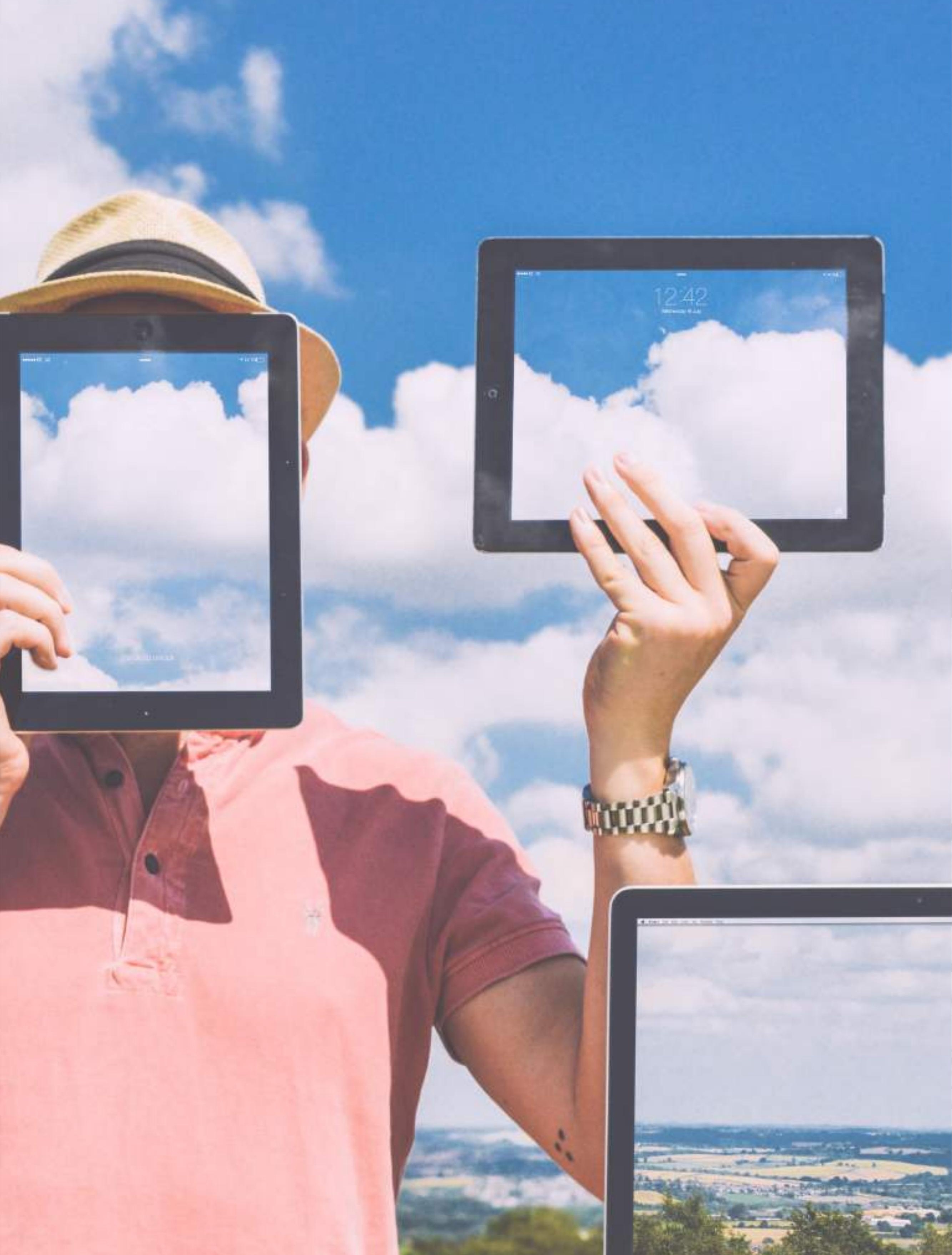




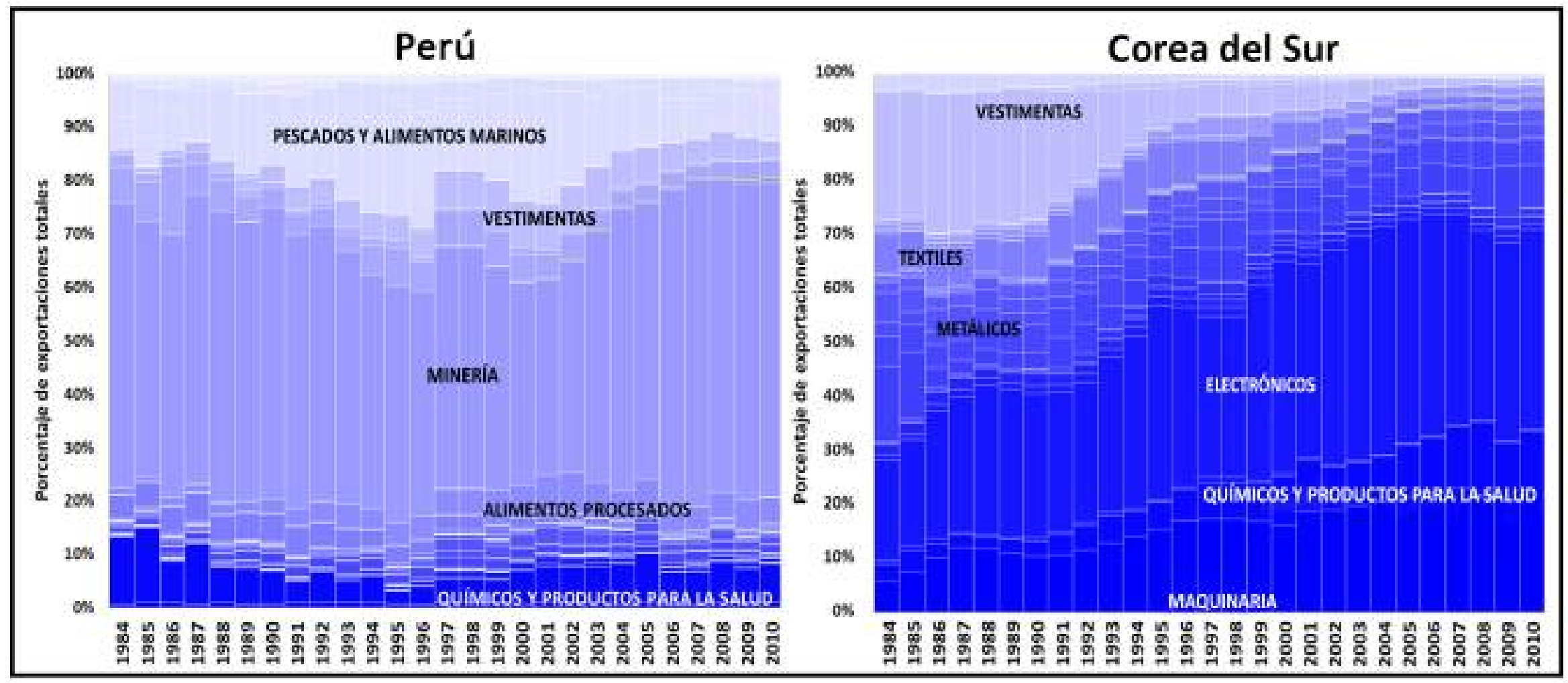

Fuente: CADE (2014)

$\mathrm{E}$ país no dependa de los precios internacionales de los minerales es desarrollar ciencia, tecnología e innovación productiva. Hace 40 años, Corea del Sur y el Perú tenían casi el mismo nivel de pobreza. Corea del Sur tiene actualmente $20 \mathrm{mi}$ llones más de habitantes que el Perú (son cerca de 50 millones de surcoreanos); sin embargo, su ingreso per cápita es ligeramente superior a los USD 30 000, mientras que el ingreso per cápita en el Perú es de solo USD 11403 (CADE, 2014). La diferencia radica en el tipo de economía que se aplica en ambos países. La nuestra se basa en el extractivismo. La economía surcoreana se basa en la innovación tecnológica producto de la investigación científica. Basta un ejemplo para demostrarlo: la empresa surcoreana Samsung factura USD 9543 por segundo (Infotechnology, 2014). En la figura 1, se muestra la dinámica de esta diferencia.
No solo nos hemos retrasado frente a Corea del Sur, país que, en 1980, tenía el mismo PBI per cápita que el nuestro. Igualmente, en la figura 2, se puede apreciar la evolución del ingreso per cápita de diferentes países en los últimos 62 años. res por cada 1000 miembros de la población económicamente activa (PEA). En el caso de Chile, esta cifra es de 2. El Perú invierte 0,15\% del PBI (USD 210000 millones) en investigación y desarrollo; Chile, el 0,5\% de su PBI (USD 268000 millo-

Figura 2. Evolución comparativa del PBI per cápita de países emergentes

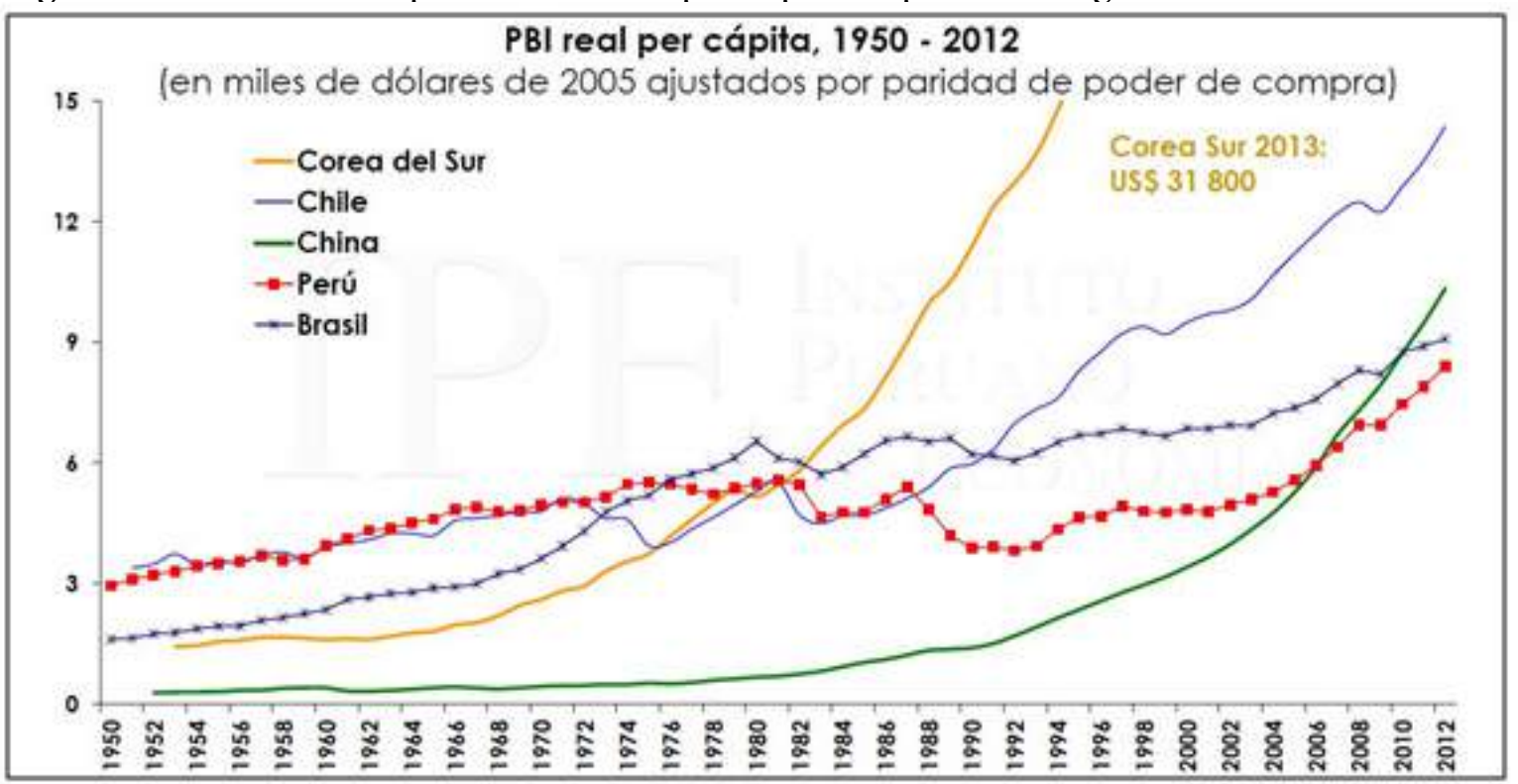

Fuente: Instituto Peruano de Economía (IPE) \& Universidad de Pennsylvania (Penn World Tables)

Si realizamos una comparación más cercana, en 2013, el Perú destinó USD 241 millones a investigación y desarrollo, mientras que Chile invirtió USD 1037 millones (4,3 veces más). El Perú tiene 0,24 investigado- nes). A todo esto, debemos agregar que la población peruana es 1,8 veces mayor que la población del vecino del sur, que no cuenta con los recursos naturales que nosotros tenemos. 
Salvo el esfuerzo de pocas universidades, en el Perú, prácticamente no se desarrolla investigación científica. Somos «esclavos tecnológicos». Dependemos mucho de la tecnología extranjera. El sector productivo peruano no es innovador, porque no se desarrolla la ciencia, sin la que es imposible crear tecnología. Los peruanos no valoramos la enorme cantidad de horas que invierte el hombre de investigación científica en la producción de un bien o servicio tecnológico. Según el Word Economic Forum (WEF), aún estamos lejos de ser un país competitivo; estamos en el puesto 65 de 148 países (WEF, 2016). Tenemos políticas destinadas a gestionar miseria y escasez en lugar de apostar por la ciencia y la tecnología, que nos llevarán a gestionar abundancia.

Urge, pues, la creación de un Ministerio de Ciencia, Tecnología e Innovación que esté constituido por todos los institutos de investigación que tenemos, y trabaje coordinadamente con las universidades y el sector empresarial productivo. Este ministerio tendría varios objetivos. En primer lugar, se encargaría de poner en valor el rol de la ciencia, tecnología e innovación en todos los niveles de nuestra sociedad. Debería lograr que se venere a los científicos, tecnólogos e innovadores como se hace con los deportistas. En segundo lugar, buscaría generar el interés por la ciencia desde la niñez, cambiar la manera de pensar de nuestros niños y jóvenes. En tercer lugar, procuraría diseñar y ejecutar el Plan Nacional de Ciencia y Tecnología priorizando el uso del agua, ahorro de energía, cuidado del ambiente, desarrollo de infraestructura y aprovechamiento de nuestros recursos naturales en los sectores de energía (hidráulica, eólica, geotérmica, de gas y petrolera), pesca, minería, agro y medio ambiente.
En cuarto lugar, necesitaría abordar el estudio científico de la conflictividad social en torno del sector extractivo, así como el incremento de la productividad, y la búsqueda de nuevos productos, servicios y mercados. En quinto lugar, se encargaría de contemplar la repatriación de científicos peruanos que actualmente viven en el extranjero dándoles incentivos. Inicialmente, esta inversión podría parecer un gasto; pero, con el paso del tiempo, estos científicos compensarían y superarían largamente lo invertido en ellos. En sexto lugar, se preocuparía por modernizar los laboratorios donde se desarrolle una labor coordinada entre el mundo académico, empresarial y el Estado. En séptimo lugar, buscaría dar facilidades tributarias y de infraestructura a las grandes corporaciones que desarrollen tecnología para que se establezcan en el Perú con la condición de que concreten la ansiada transferencia tecnológica. Por último, tendría que definir qué producto, cuánto y a qué costo fabricarlo para alcanzar competitividad global. Todo esto es posible. Otros países que no cuentan con los recursos naturales que tenemos lo han logrado, por ejemplo, Argentina. ¿Por qué no podemos hacerlo los peruanos?

Es el desarrollo de la ciencia y la tecnología lo que nos proporcionará competitividad como país. Sin embargo, en la lista global de competitividad 2014-2015, elaborada por el WEF (2014), el Perú bajó cuatro posiciones y se ubicó en el puesto 65 de 143 economías, lo que nos lleva al puesto 6 en América Latina. En contraste, Chile ocupa el primero a nivel de Latinoamérica y el puesto 33 a nivel global. Los pilares que se analizan para elaborar el Índice de competitividad global (GCI por sus siglas en inglés) son doce: institucionalidad, infraestructura, ambiente macroeconómico estable, salud y educación primaria adecuada, educación superior y capacitación, funcionamiento eficiente del mercado de bienes y servicios, eficiencia del mercado laboral, desarrollo del mercado financiero, desarrollo tecnológico, tamaño del mercado, sofisticación empresarial e innovación (GCI, 2016).

La competitividad es el medio para lograr el crecimiento económico como país y generar desarrollo humano. Imaginar el Perú como un país del primer mundo no es una utopía. Aún mantenemos una brecha en nuestro camino para ser uno de los países que conforman la Organización para la Cooperación y el Desarrollo Económico (OCDE), la misma que actualmente agrupa a los 34 países más desarrollados del planeta y cuyo fin es «promover políticas que mejoren el bienestar económico y social de las personas alrededor del mundo». El promedio de ingreso de los países que forman parte de ella es USD 37 275; el peruano, USD 11 775. Alcanzar esa cifra, creciendo al $3 \%$ anual, con un incremento poblacional de 1,3 , nos tardaría 70 años; al $5 \%$ anual, 33; y, al $7 \%$, 22. En la tabla 1, se puede observar la brecha que existe entre los indicadores analizados.

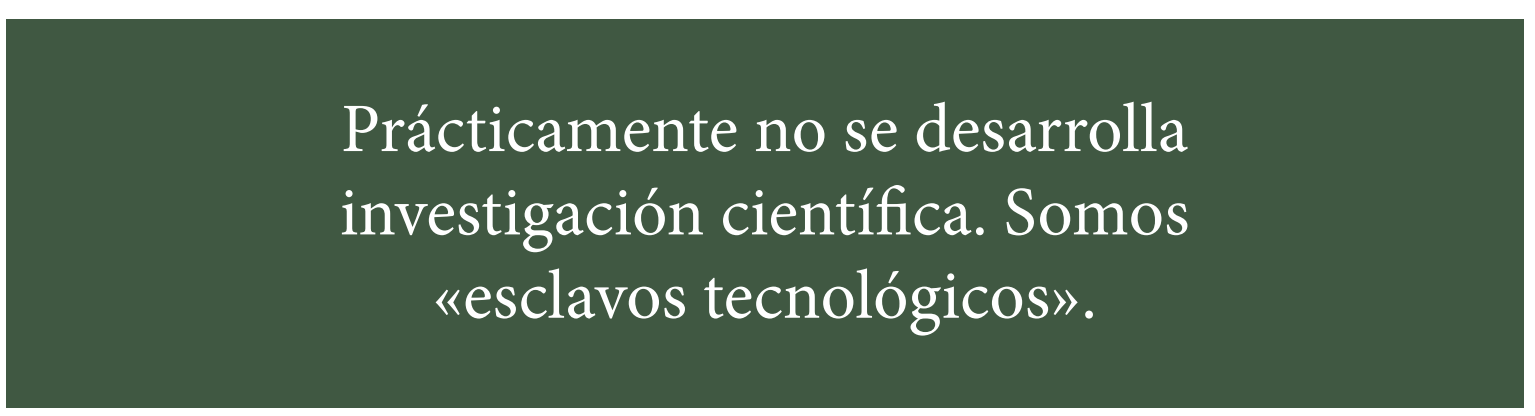


A nivel interno, el Instituto Peruano de Economía (IPE) elabora anualmente el Índice de competitividad regional (Incore), en el que se muestra la competitividad de todas las regiones políticas del Perú siguiendo los mismos parámetros de medición que la WEF aplica, tal como se puede ver en la figura 3. Nótese que las regiones de la costa son las más competitivas, a las que se agrega Madre de Dios. Además, urge elevar la competitividad regional mediante el desarrollo de infraestructura.
En la figura 4, se presenta una comparación del valor agregado industrial que colocamos a nuestra producción industrial. Llama la atención la enorme brecha que nos separa no solo respecto de los países industrializados, sino también de los de América Latina.

Tabla 1

Indicadores de desarrollo diversos del Perú respecto a países de la OCDE

\begin{tabular}{|lcc|}
\hline \multicolumn{1}{|c|}{ INDICADORES WEF 2014-2015 (144 PAÍSES) } & PERÚ \\
\hline Institucionalidad & 39 & 118 \\
\hline Infraestructura & 26 & 88 \\
\hline Salud y educación primaria & 28 & 94 \\
\hline Educación superior y capacitación & 25 & 83 \\
\hline Marco macroeconómico & 60 & 21 \\
\hline Disposición tecnológica & 24 & 92 \\
\hline Innovación & 27 & 117 \\
\hline
\end{tabular}

Fuente: Word Economic Forum (WEF)

Figura 3. Indicadores de competitividad en el Perú por regiones

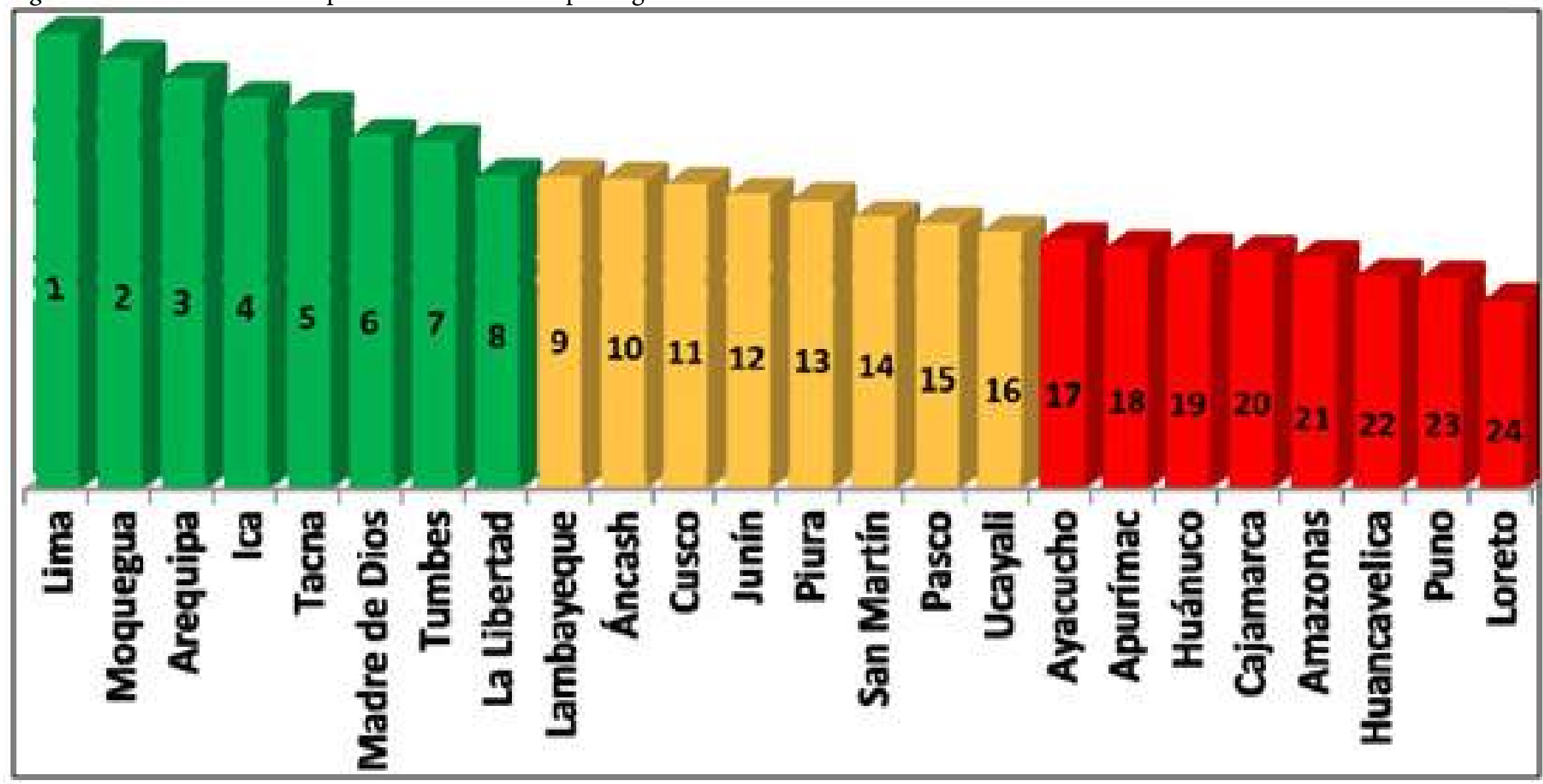

Fuente: Instituto Peruano de Economía (IPE) 
Sugiero que los partidos políticos, el Gobierno, los medios de comunicación, los colegios profesionales, las universidades y demás instituciones abordemos este tema con carácter de urgencia. En el Perú, se ha perdido demasiado tiempo. Tenemos una deuda pendiente con nuestra niñez y

\section{Tenemos una deuda pendiente con nuestra niñez y juventud.}

Figura 4. Comparación del valor agregado industrial del Perú y de los países industrializados del mundo

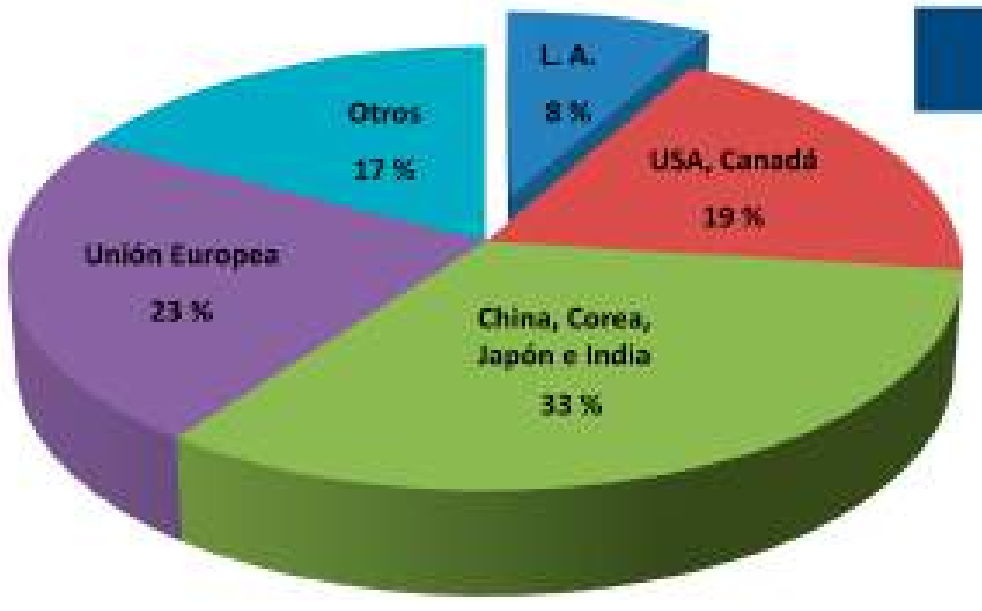

MUNDO
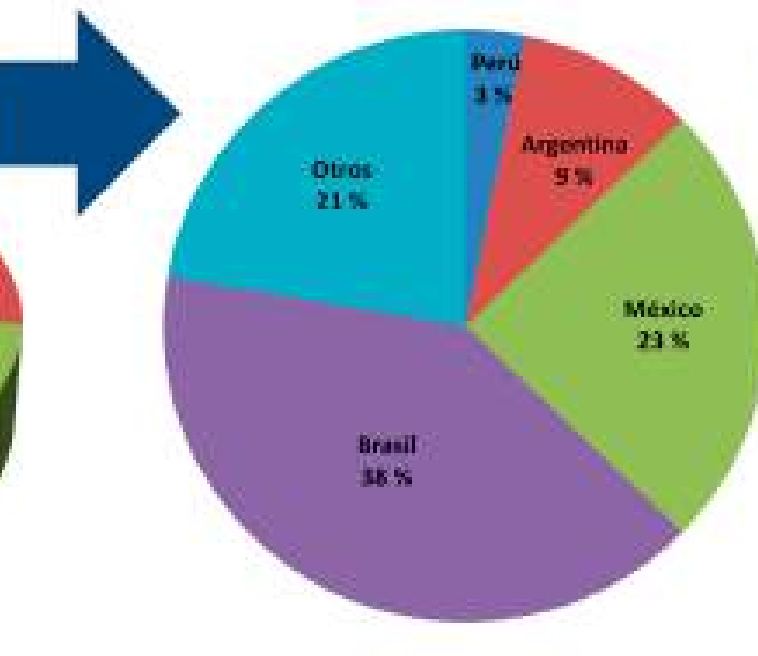

AMÉRICA

LATINA

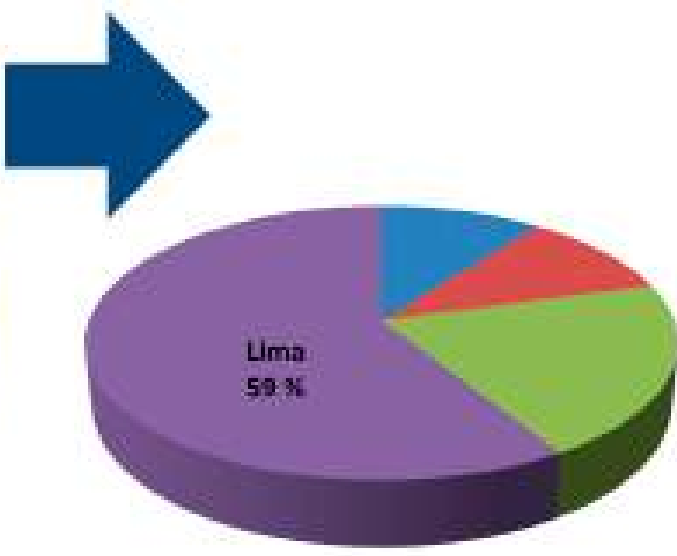

PERÚ

$0,2 \%$ DEL MUNDO

Fuente: Banco Mundial \& INEI

juventud. En la figura 5, se muestra como tendencia favorable que, cuando se invierte en capacidades vitales en una etapa más temprana de la vi$\mathrm{da}$, las perspectivas futuras mejoran.

El Perú de hoy tiene todas las condiciones para, a corto plazo, llegar a ser un país del primer mundo. El principal obstáculo que tenemos que vencer es que la mayoría de peruanos no tengamos visión de futuro. Tenemos que fortalecer nuestras competencias individuales, apostar decididamente por la educación $\mathrm{y}$, sobre todo, creer en nosotros mismos. Las universidades tienen un rol fundamental en ese sentido por su labor en la formación de nuevos profesionales.
Figura 5. Comportamiento de tendencias de capacidades humanas

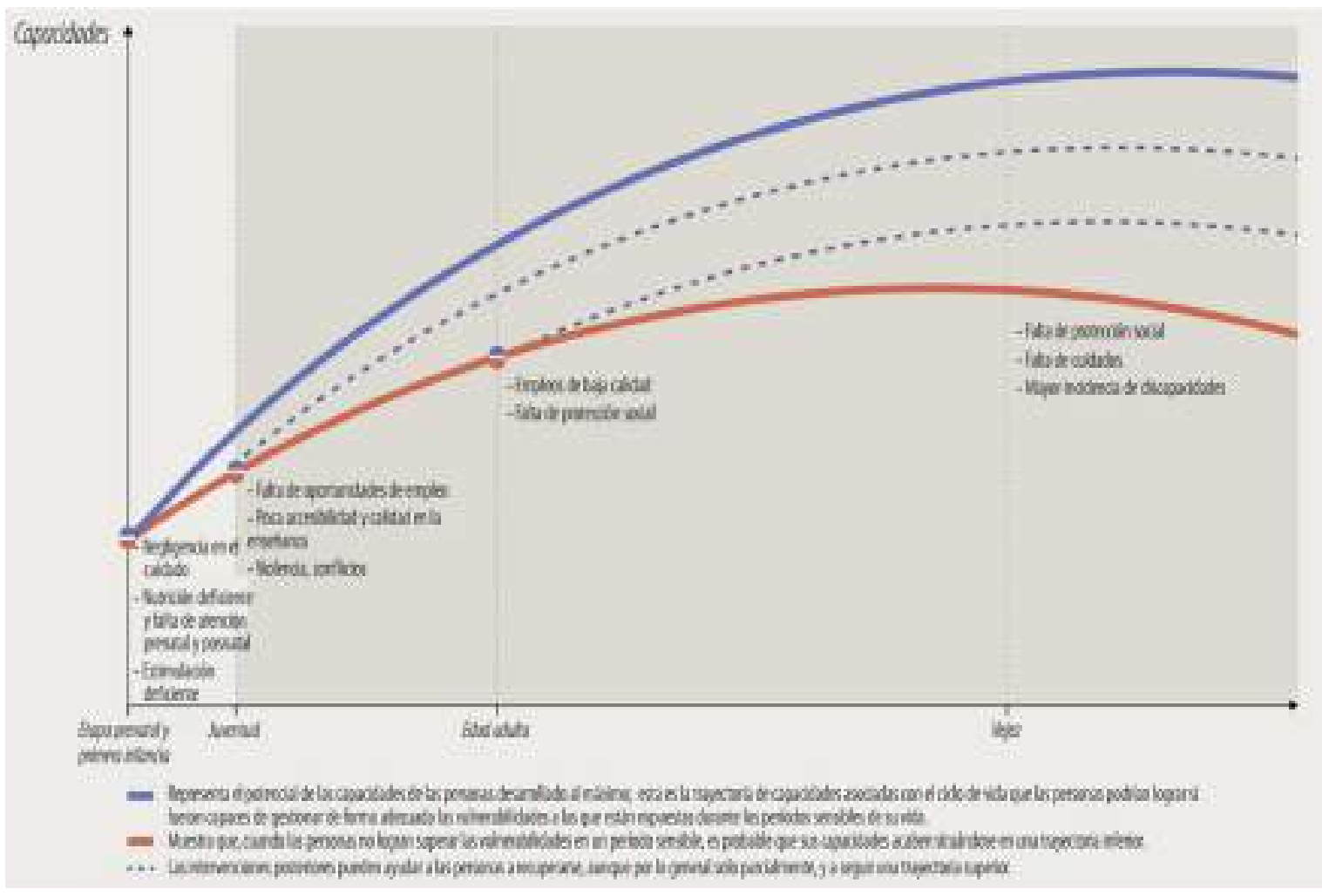

Fuente: Oficina sobre Desarrollo Humano, Perú

\section{Imaginar el Perú como un país del primer mundo no es una utopía.}

